\title{
Transplante cardíaco e infecção
}

\author{
Wilson José COUTO*, João Nelson R. BRANCO*, Dirceu ALMEIDA*, Antonio C. CARVALHO*, \\ Rodrigo VICK*, Carlos A. TELES*, Luciano F. AGUIAR*, Enio BUFFOLO*
}

RBCCV 44205-541

Couto W J, Branco J N R, Almeida D, Carvalho A C, Vick R, Teles C A, Aguiar L F, Buffolo E Transplante cardíaco e infecção. Rev Bras Cir Cardiovasc 2001; 16(2): 141-51.

RESUMO: Objetivo: O presente estudo visa avaliar a incidência de infecções, os agentes etiológicos, e a apresentação clínica e a morbi-mortalidade operatória nos pacientes submetidos a transplante cardíaco na Universidade Federal de São Paulo.

Casuística e Métodos: No período de novembro de 1996 a junho de 1998, 97 pacientes transplantados pela equipe de Cirurgia Cardiovascular da UNIFESP sobreviveram por período superior a uma semana após o transplante e foram analisados, retrospectivamente, quanto aos processos infecciosos diagnosticados. A idade dos pacientes variou de 3 a 63 anos (média de 44,4 13,0 anos), sendo que a maioria apresentava miocardiopatia dilatada (46), seguida de chagásica (24) e isquêmica (23). O tempo de seguimento variou de 0,33 a 119 meses (36 30,7 meses).

Resultados: Dos 97 pacientes estudados, 16 (16,4\%) morreram, sendo infecção a principal causa, seguido pela rejeição em 10 (10,30\%). As causas de óbito por infecção foram: sepse bacteriana em 6 pacientes, pneumonia em outros 6 , infecção intra-abdominal em 2, toxoplasmose disseminada em 1 e infecção pelo citomegalovírus em 1. Ocorreram 142 episódios infecciosos diagnosticados distribuídos da seguinte forma: bacterianos 76 (52,5\%); virais 34 (28,8\%); fúngicos 20 (17,5\%) e protozoários 12 $(12,4 \%)$. Houve 8 episódios de reativação da doença de Chagas (média 4,9 meses após o transplante) diagnosticados principalmente através do aparecimento de nódulos subcutâneos. Todos os casos de reativação foram tratados com alopurinol e evoluíram bem.

Conclusão: Os dados apresentados mostraram o predomínio de infecções bacterianas que causaram maior mortalidade. Nos transplantados por doença de Chagas a reativação da doença pode ser controlada adequadamente com uso de alopurinol. Os dados são importantes para orientação em nossa comunidade dos programas de transplantes, uma vez que traz à tona particularidades do nosso meio.

DESCRITORES: Transplante de coração, infecção. Transplante de coração, mortalidade. Transplante de coração, efeitos adversos. Infecção, epidemiologia. Infecção, etiologia. Infecção, mortalidade.

\section{INTRODUÇÃO}

O transplante cardíaco entre humanos realizado pioneiramente por BARNARD (1) representou o início de importantes avanços no tratamento dos pacientes acometidos por doença cardíaca terminal.
No Brasil, essa nova modalidade de tratamento cirúrgico foi introduzida por Zerbini (2). Nos últimos anos, a realização de transplantes cardíacos, em sua maioria ortotópicos, tem se tornado rotineira e pode-se afirmar que o seu crescimento é notável ao redor do mundo e também no Brasil.

\footnotetext{
Trabalho realizado na Universidade Federal de São Paulo - Escola Paulista de Medicina, São Paulo, SP, Brasil. Apresentado ao 27ํㅡㄹ Congresso Nacional de Cirurgia Cardíaca. Rio de Janeiro, RJ, 23 a 25 de março, 2000.

*Da Universidade Federal de São Paulo - Escola Paulista de Medicina.

Endereço para correspondência: Wilson Couto. Rua Borges Lagoa, 783 - 5a andar. São Paulo, SP, Brasil. CEP 04038 -031. Tel: (11) 573-3009. Fax: (11) 573-0303.e-mail: cardiovascular.dcir@epm.br
} 
As taxas de sobrevida após o transplante são consideradas aceitáveis, sendo que vários fatores contribuíram para tal fato, dentre eles cita-se a introdução da Ciclosporina A, em dezembro de 1980, que possibilitou um controle mais adequado dos episódios de rejeição, mesmo com potenciais efeitos colaterais.

Apesar de todo o aprimoramento, a infecção permanece como uma das principais causas de morbidade e mortalidade após o transplante, mesmo com a utilização de modernos antimicrobianos. Tal fato ocorre devido ao tratamento imunossupressor que, embora essencial para a sobrevivência dos pacientes operados a longo prazo, leva ao comprometimento das defesas imunológicas do organismo (principalmente dos linfócitos $\mathrm{T}$ e B) e aumenta a probabilidade de infecção.

A freqüência e a intensidade do processo infeccioso estão diretamente relacionadas ao grau de imunodepressão necessário para prevenir ou tratar os episódios de rejeição. Alguns fatores podem influenciar o surgimento ou não de processos infeciosos como a presença concomitante de doenças crônicas, a escolha do doador, técnica cirúrgica adequada e o perfil psicossocial do receptor $^{(3)}$.

Os agentes infecciosos podem ser transmitidos ao receptor pelo órgão do doador, através de transfusão de sangue e seus derivados ou por situações próprias do ambiente hospitalar. Os processos infecciosos também podem ocorrer por meio da participação da flora endógena e reativação de infecções latentes previamente adquiridas (3).

No Brasil, UIP (3) realizou importante estudo que mostrou as características dos processos in fecciosos nos pacientes submetidos a transplante cardíaco no Instituto do Coração do Hospital das Clínicas da Faculdade de Medicina da Universidade de São Paulo.

No período de novembro de 1986 a junho de 1998, foram realizados 105 transplantes cardíacos pela equipe de cirurgia cardiovascular do setor de transplantes cardíacos da Universidade Federal de São Paulo - Escola Paulista de Medicina ${ }^{(4)}$.

O conhecimento detalhado desses pacientes no que diz respeito à incidência de infecção, bem como, seus agentes responsáveis e seu impacto clínico, se revestem de importância para melhor entendimento e controle futuro do binômio infecção-rejeição. O presente estudo tem por objetivo avaliar a incidência de infecção, os agentes etiológicos, sua topografia, apresentação clínica e a morbi-mortalidade operatória decorrente dos processos infecciosos nesse grupo de pacientes.

\section{CASUÍSTICA E MÉTODOS}

No período de novembro de 1986 a junho de 1998, realizaram-se 105 transplantes cardíacos ortotópicos pela equipe de cirurgia cardiovascular do setor de transplantes cardíacos da Universidade Federal de São Paulo - Escola Paulista de Medicina.

Dos 105 transplantados, 97 sobreviveram período superior a uma semana após o transplante, tendo sido analisados, retrospectivamente, no que diz respeito aos processos infecciosos diagnosticados.

O tempo de seguimento, após a alta hospitalar variou de 0,33 a 119 meses, com média de 36 30,7 meses, ressaltando-se que 78 pacientes eram do sexo masculino e 19 do feminino. A idade média variou de 3 a 63 anos, com média de 44,4 13,0 anos.

As etiologias das cardiomiopatias que motivaram a realização do transplante foram: dilatada em $46(47,4 \%)$, chagásica em $24(24,7 \%)$, isquêmica em $23(23,7 \%)$, valvar em $2(2,1 \%)$ e outras miocardiopatias em $2(2,1 \%)$ pacientes como mostra na Figura 1.

Dos 97 pacientes avaliados, 21 apresentavam operação cardíaca prévia.

Os doadores e receptores foram avaliados através de protocolo específico do setor de transplantes da UNIFESP.

A técnica operatória empregada foi a clássica de transplante ortotópico descrita e padronizada por LOWER \& SHUMWAY (5).

A profilaxia antimicrobiana utilizada consistiu de cefalotina ou cefazolina, $1,0 \mathrm{~g}$ endovenosa a cada 6 horas, iniciada na indução anestésica e mantida até a retirada dos cateteres, drenos e sondas (tempo médio de 3 a 5 dias). Foi utilizado nistatina 200.000 $\mathrm{UI}$ via oral a cada 6 horas por 10 a 12 dias. Não foram incluídas no esquema profilático drogas antivirais de uso tópico ou sistêmico.

O protocolo de imunossupressão, usado rotineiramente, foi baseado no clássico esquema "tríplice" (corticóides, azatioprina e ciclosporina) com algumas adaptações. Particularmente, nos pacientes chagásicos, a partir do $3^{\circ}$ mês, a prednisona foi interrompida. O diagnóstico e manutenção da rejeição celular foram efetuados por meio de biópsia endomiocárdica.

Após a operação, os pacientes permaneceram na Unidade de Terapia Intensiva, em box isolado, por tempo aproximado de uma semana. A manipulação do paciente pelo pessoal médico e paramédico 


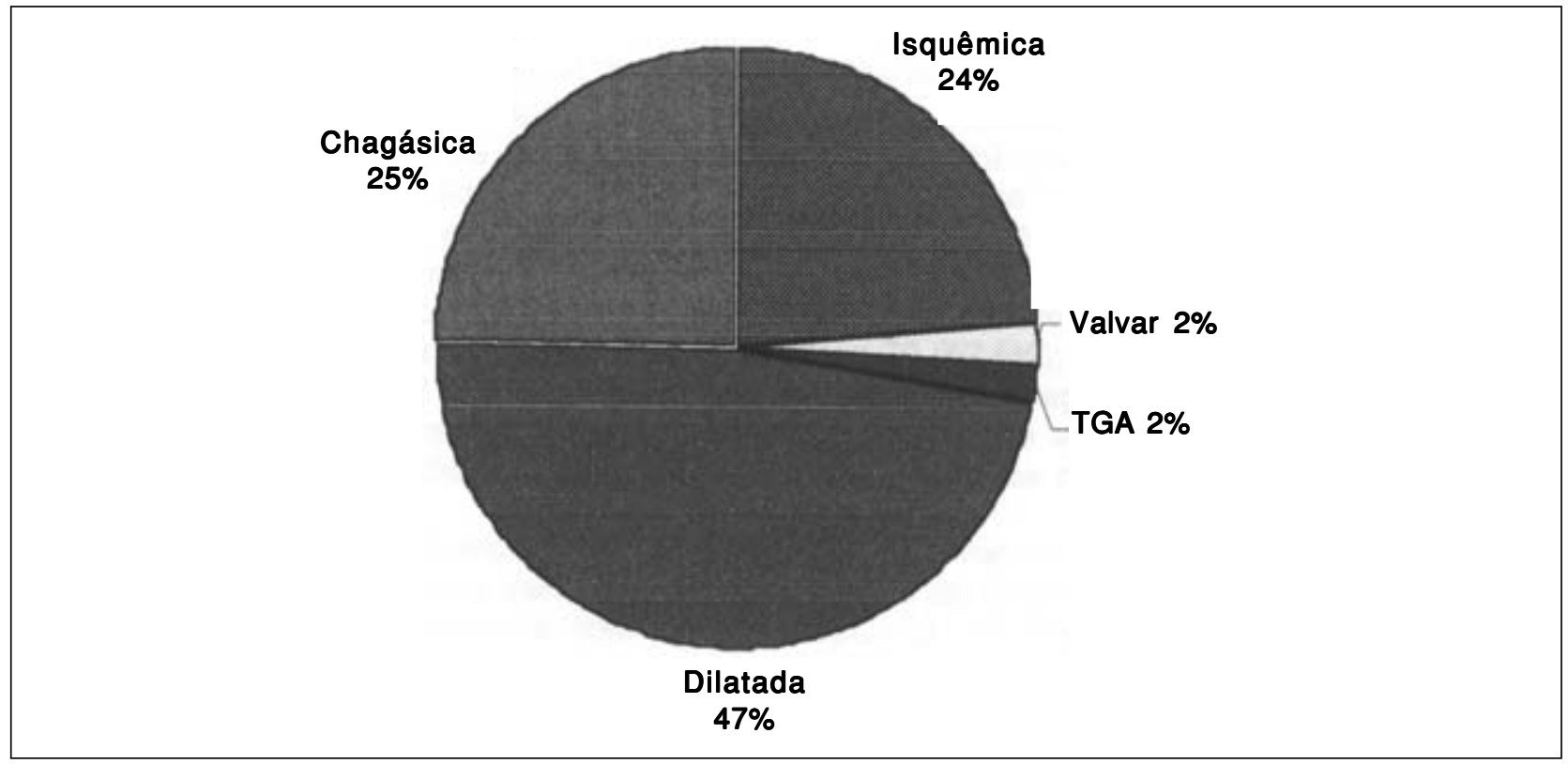

Fig. 1 - Miocardiopatia - indicações de transplante cardíaco.

foi cuidadosa, respeitando-se as técnicas de antissepsia, com lavagem regular das mãos, uso de máscaras, gorros, aventais e luvas. No segundo dia de pós-operatório, foram retirados o cateter da artéria radial, a sonda vesical e o dreno mediastinal. No quarto dia foi retirado o cateter de "Swan-Ganz".

$\mathrm{Na}$ avaliação dos processos infecciosos solicitaram-se exames laboratoriais específicos e inespecíficos, de acordo com a rotina do Serviço e quadro clínico apresentado pelo paciente.

O diagnóstico da maioria das infecções obedeceu os critérios utilizados pelo grupo de Cardiologia Clínica responsável pelo acompanhamento dos pacientes em conjunto com os médicos do Departamento de Doenças Infecciosas e Parasitárias (DIPA) da UNIFESP. Tais critérios basearam-se nas definições estabelecidas pelos Centers for Disease Control (6).

O diagnóstico de reativação da infecção pelo Trypanosoma cruzi foi estabelecido mediante o quadro clínico e a detecção de parasitas no sangue ou tecidos. O diagnóstico de miocardite chagásica foi realizado pela presença de Tripanosoma cruzi associado a infiltrado inflamatório do miocárdio ou biópsia de pele (7).

As variáveis estudadas foram a incidência de infecção por paciente-período; os agentes etiológicos e as respectivas topografias, apresentação clínica; métodos de diagnóstico; causa de óbitos e taxas de sobrevida.

\section{Análise Estatística}

A análise estatística dos dados foi realizada através da análise descritiva: valores mínimo e máximo, média e desvio padrão para as variáveis quantitativas e proporção para as variáveis qualitativas.

A sobrevida dos pacientes foi analisada através da técnica da curva de Kaplan-Meier. Esses dados foram também analisados para pacientes com e sem infecção, sendo a comparação entre esses dois grupos realizada através do teste de Log-Rank ao nível de significância de 5\%.

O tempo livre de reativação da doença de Chagas também foi analisado através da técnica de curva de sobrevida de Kaplan-Meier.

\section{RESULTADOS}

Dos 97 pacientes estudados, $16(16,4 \%)$ morreram devido à infecção. Essa foi a principal causa de óbito nos pacientes transplantados, seguida pela rejeição em 10 (10,3\%) pacientes.

As causas de óbito devido à infecção estão mostrados na Figura 2 e foram: sepse bacteriana em 6 pacientes, pneumonia em 6 , infecção intra-abdominal em 2, toxoplasmose disseminada em 1 e infecção sistêmica por citomegalovírus em 1. 


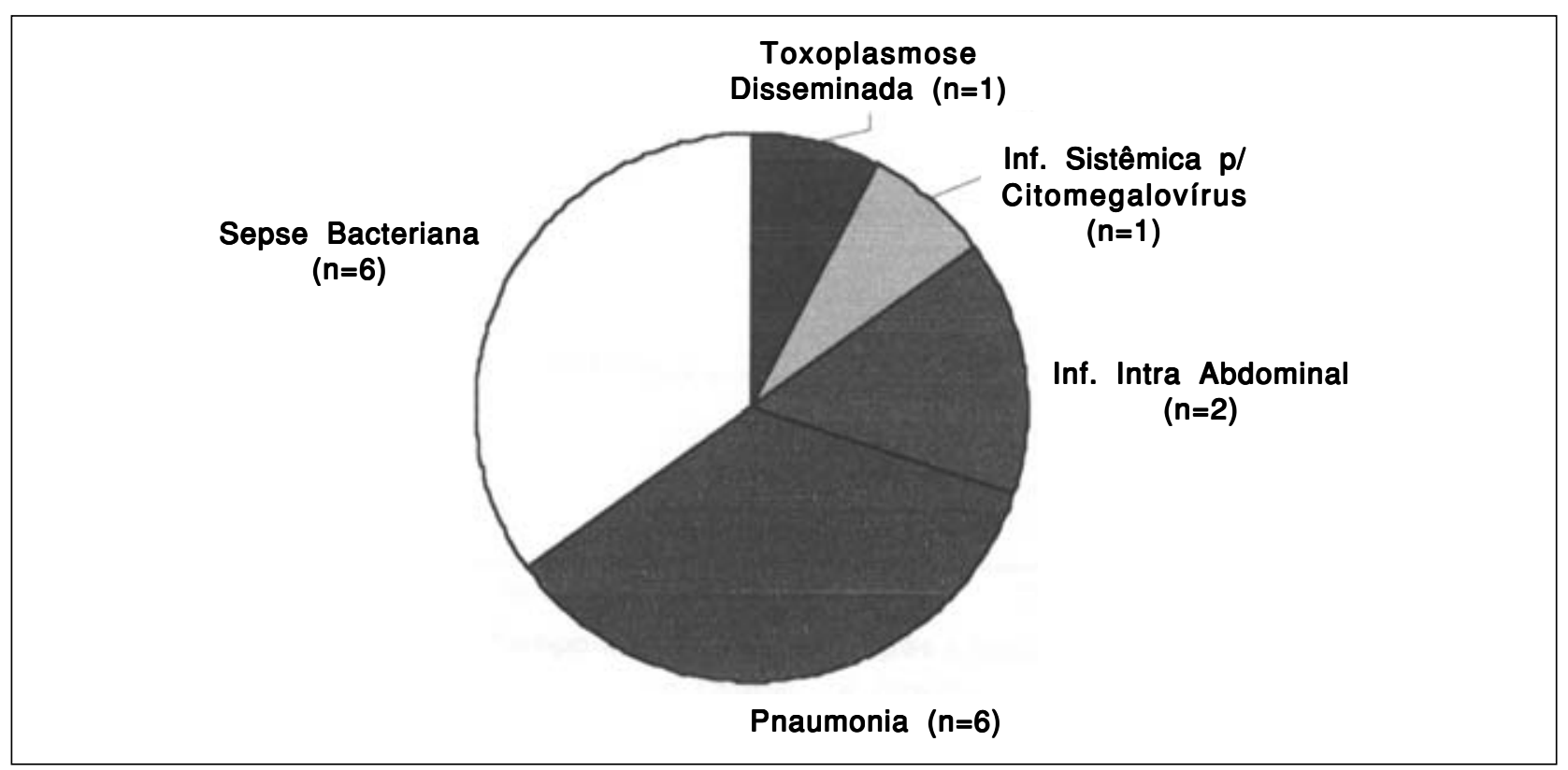

Fig. 2 - Causas de óbito devido a infecções.

A curva de sobrevida dos pacientes após a operação (Kaplan-Meier), com e sem infecção diagnosticada, está demonstrada no Gráfico 1, não se notando diferença estatisticamente significante os dois grupos.

Ocorreram 142 episódios infecciosos diagnosticados segundo os critérios estabelecidos. A distribuição quanto à etiologia ocorreu da seguinte forma: bacteriana $76(52,5 \%)$, viral $34(28,8 \%)$, fúngica $20(17,5 \%)$ e protozoária $12(12,4 \%)$, conforme demonstrado na Tabela 1.

A curva indicando a probabilidade livre de infecção no decorrer do tempo após o transplante está demonstrada no Gráfico 2.

\section{Infecções Causadas por Bactérias}

O número de infecções causadas por bactérias em relação ao número de pacientes está demonstrado no Gráfico 3.

Segundo os critérios estabelecidos, ocorreram 26 pneumonias com 6 óbitos. Notou-se predominância de agentes gram negativos nos casos em que foram cultivados os prováveis agentes, principalmente,através da colheita de secreção traqueal.

Em 2 pacientes observou-se empiema pleural causada por Staphylococcus aureus em um e Acinetobacter em outro.

TABELA 1

NÚMERO E PORCENTAGEM DE PACIENTES SEGUNDO O TIPO E NÚMERO DE INFECÇÕES

\begin{tabular}{|c|c|c|c|c|c|c|c|c|c|c|}
\hline \multirow[t]{2}{*}{ № INFECÇŌES } & \multicolumn{2}{|c|}{ BACTÉRIAS } & \multicolumn{2}{|c|}{ VÍRUS } & \multicolumn{2}{|c|}{ PROTOZOÁRIOS } & \multicolumn{2}{|c|}{ FUNGOS } & \multicolumn{2}{|c|}{ TOTAL } \\
\hline & $n$ & $\%$ & n & $\%$ & & $\%$ & n & $\%$ & $n$ & $\%$ \\
\hline 0 & 46 & 47,4 & 69 & 71,1 & 85 & 87,6 & 80 & 82,5 & 30 & 0,9 \\
\hline 1 & 33 & 34,0 & 24 & 24,7 & 12 & 12,4 & 14 & 14,4 & 33 & 34,0 \\
\hline 2 & 11 & 11,3 & 3 & 3,1 & & & 3 & 3,1 & 12 & 12,4 \\
\hline 3 & 7 & 7,2 & - & - & - & - & - & - & 10 & 10,3 \\
\hline 4 & - & - & 1 & 1,0 & - & - & - & - & 7 & 7,2 \\
\hline 5 & - & - & - & - & - & - & - & - & 4 & 4,1 \\
\hline 6 & - & - & - & - & - & - & - & - & 1 & 1,0 \\
\hline
\end{tabular}




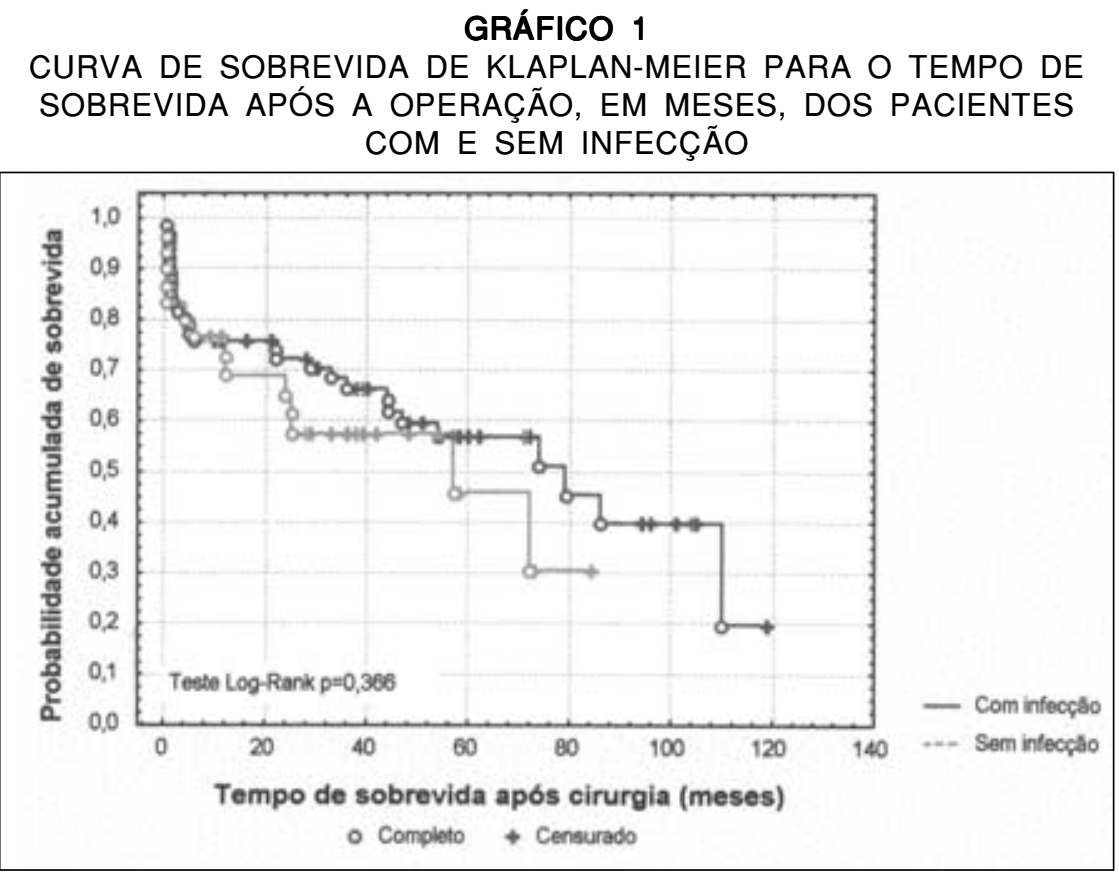

\section{GRÁFICO 2}

CURVA DE SOBREVIDA DE KAPLAN-MEIER PARA O TEMPO

LIVRE DE INFECÇÃO APÓS A OPERAÇÃO, EM MESES

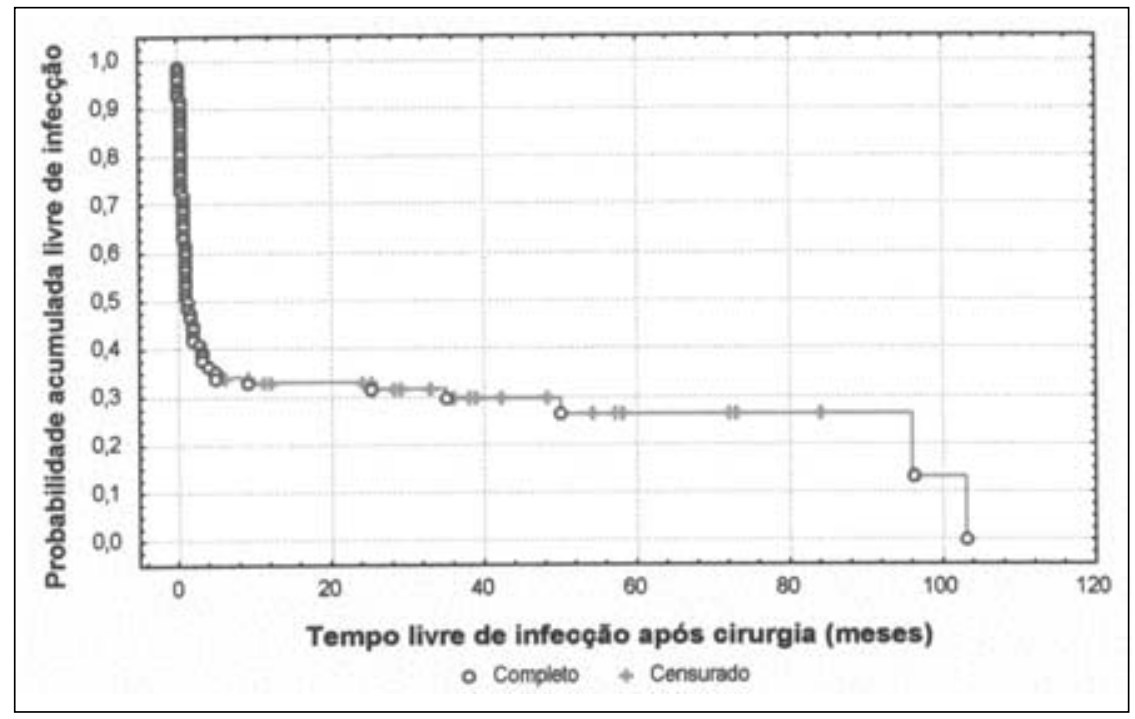

Houve 9 infecções do trato urinário, todas causadas por agentes negativos, que apresentaram boa evolução após tratamento específico.

Em 6 ocasiões observou-se sepse, todas com evolução fatal. Observamos 5 infecções superficiais do sítio cirúrgico, causadas principalmente por agentes gram positivos, predominando o Staphylococcus aureus. Notamos 4 infecções profundas do sítio cirúrgico, causadas por Staphylococcus aureus em 2 pacientes, Staphylococcus epidermis em 1, Klebsiela em 1, Enterobacter em 1 paciente. Não ocorreram óbitos nos pacientes com infecção do sítio cirúrgico, sendo necessária reintervenção operatória em 3 pacientes. Houve 6 casos de sinusite e 1 de otite, com boa evolução. 

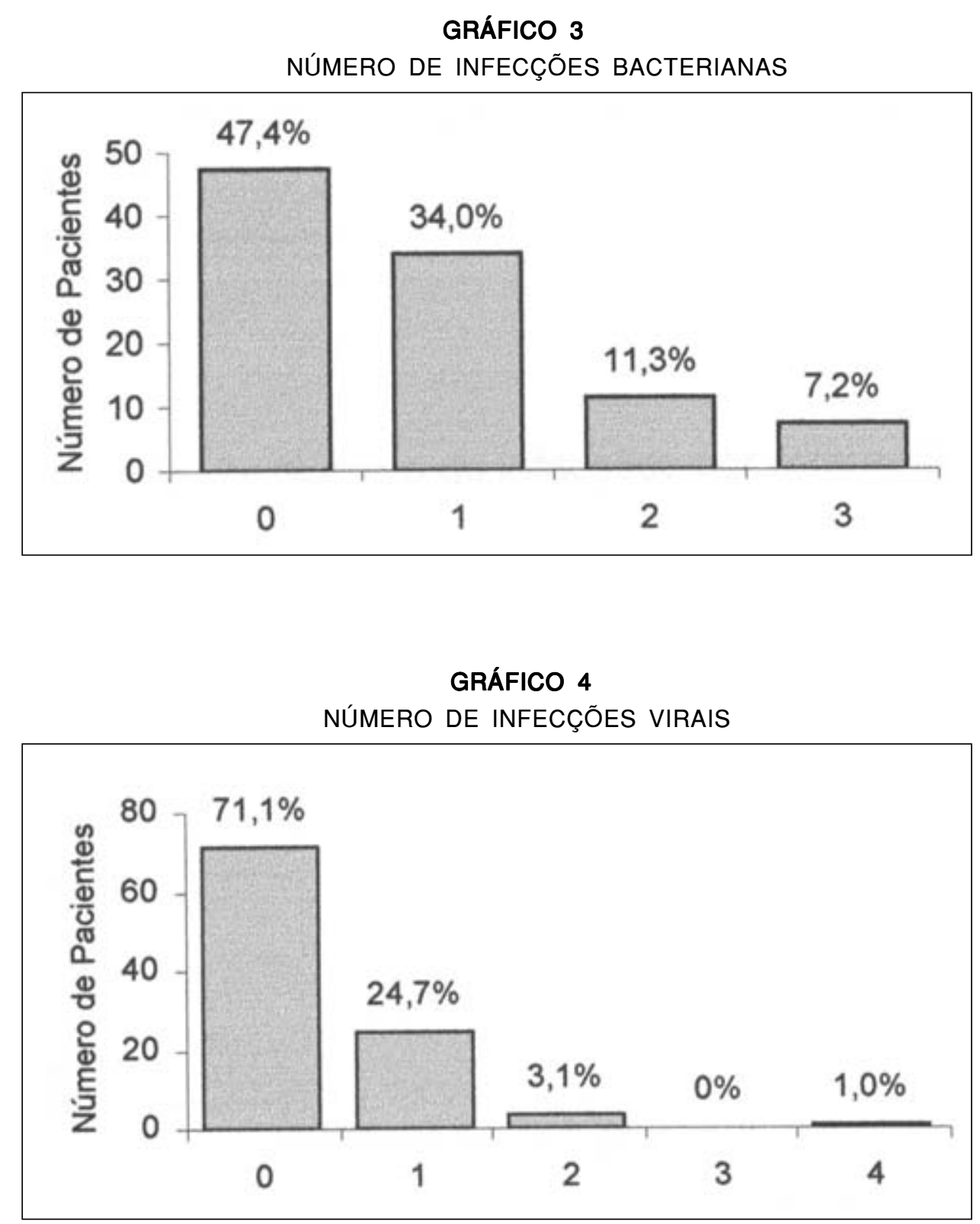

As infecções intra-abdominais, em número de 4, causaram 2 óbitos: um secundário ao uso de cateter de diálise peritoneal e outro devido à pancreatite e intervenção cirúrgica abdominal. As infecções de pele, mucosa e partes moles foram assim distribuídas: 4 foliculites, 3 celulites, 2 abscessos e 1 furúnculo.

Uma paciente apresentou abscesso cerebral por Listeria monocytogenes com boa evolução após antibioticoterapia e drenagem. Outro paciente evoluiu com infecção da corrente sangüínea sem foco determinado e sem repercussões graves.

\section{Infecções Causadas por Vírus}

O Gráfico 4 mostra o número de infecções por vírus em relação ao número de pacientes. Houve um predomínio de infecções causadas pelo vírus herpes "Simplex", sendo que sua distribuição quanto à topografia ocorreu da seguinte forma: em 9 ocasiões na cavidade oral, 9 no aparelho genital, no sistema nervoso em 1 e em córnea em 1. Observamos também 13 infecções pelo vírus varicela-zoster.

Nesse grupo ocorreu um óbito com 4 meses de pós-operatório causado por infecção disseminada pelo Citomegalovírus. 

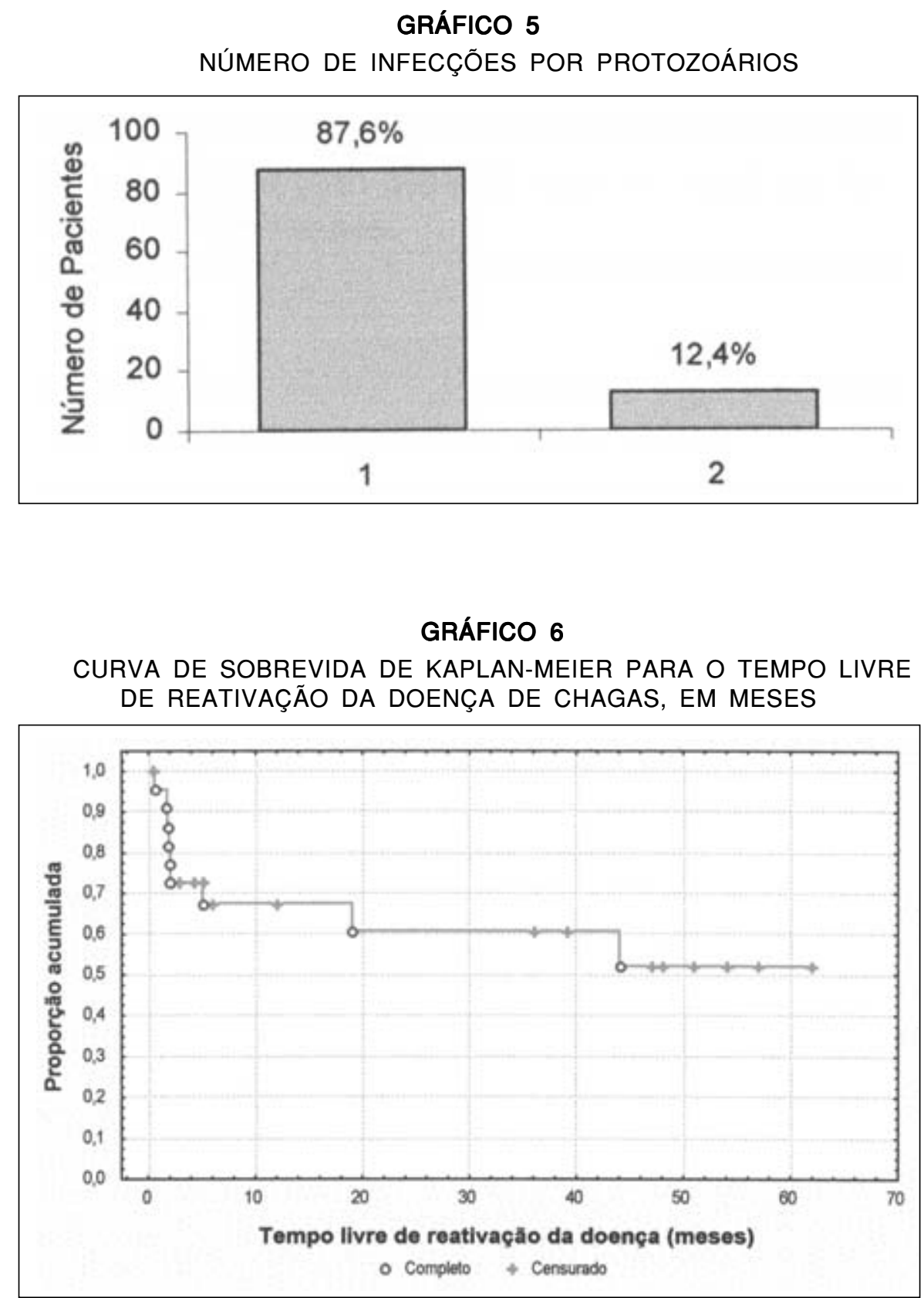

Infecções Causadas por Fungos

A maioria das infecções causadas por fungos foram sem gravidade, predominando a Candidíase oral em 14 ocasiões. Houve 1 caso de esofagite estenosante causada por Candida albicans que apresentou boa evolução após tratamento.

Também observamos duas infecções pulmonares causadas por Pneumocystis carinii.

Não ocorreram óbitos causados por esses agentes.
Infecções Causadas por Protozoários

O número de infecções causadas por protozoários em relação ao número de pacientes está demonstrado no Gráfico 5.

Dos 24 pacientes transplantados portadores de miocardiopatia chagásica, $8(33,3 \%)$ apresentaram reativação da doença. $O$ tempo médio de reativação após o transplante foi de 4,9 meses. A forma principal de ressurgimento da doença foi através do 
aparecimento de nódulos subcutâneos, principalmente em membros inferiores, em 6 pacientes. Nos outros 2 pacientes a reativação ocorreu através da manifestação de miocardite.

Todos esses episódios foram tratados com alopurinol por tempo médio de 3 meses, com boa evolução.

O Gráfico 6 mostra a porcentagem de pacientes chagásicos livres de reativação da doença no decorrer do tempo.

Ocorreram 4 casos de infecção pelo Toxoplasma gondii. O primeiro paciente apresentou no $24^{\circ}$ dia de pós-operatório quadro disseminado e óbito, sendo a causa confirmada por necropsia. Nos segundos e terceiros pacientes a apresentação clínica deu-se através da presença de coriorretinite bilateral no $6^{\circ}$ e $12^{\circ}$ meses de pós-operatório, respectivamente.

No último caso, o paciente apresentou, com um mês de pós-operatório, quadro febril prolongado, sendo evidenciados os trofozoitos de Toxoplasma gondii em biópsia miocárdica. Todos os 3 últimos pacientes apresentaram evolução favorável ao tratamento específico.

\section{COMENTÁRIOS}

O risco de infecção em pacientes submetidos a transplante cardíaco é determinado principalmente por dois fatores: a intensidade da exposição a patógenos potenciais e o grau de imunodepressão.

O grau de imunodepressão que ocorre nos pacientes transplantados, e que tem relação direta com infecção, é o resultado de uma interação complexa de vários fatores. Dentre esses fatores citamse: a dose, duração e seqüência temporal de terapia imunossupressora; a presença ou ausência de infecção causada por vírus imunomoduladores (Citomegalovírus, Epstein-Barr) e complicações resultantes de problemas técnicos cirúrgicos como a presença de tecidos desvitalizados, coleções não drenadas, cateteres invasivos. Além disso, condições metabólicas predisponentes, como uremia e má nutrição, podem também contribuir para o grau geral de imunossupressão do paciente (8).

O risco do paciente transplantado cardíaco apresentar infecção é esquematicamente organizado em 3 períodos: infecções no primeiro mês de pós-operatório, até 6 meses e mais de 6 meses.

As infecções que ocorrem no primeiro mês após o transplante, na maioria das vezes são as mesma infecções hospitalares bacterianas ou causadas por
Candida albicans e localizadas na ferida cirúrgica, pulmões, trato urinário ou acessos vasculares que ocorrem também em pacientes cirúrgicos sem imunossupressão. As infecções do primeiro mês também podem ter sido transmitidos pelo enxerto.

Após o primeiro mês de pós-operatório e até o sexto mês aparecem novos tipos de infecção, principalmente as viroses imunomoduladoras: Citomagalovírus, Epstein-barr, Herpes, etc. A combinação de imunossupressão sustentada e essas infecções virais torna possível as infecções oportunistas por Pneumocystis carinii e Lysteria monocytogenes.

No período superior a 6 meses após o transplante a maioria dos pacientes é mantida com terapia imunossupressora mínima. Os problemas infecciosos são semelhantes ao da população em geral e são principalmente respiratórios. As infecções oportunistas são ocasionais, a menos que a exposição ambiental tenha sido intensa.

O conhecimento dessa provável distribuição epidemiológica dos agentes causadores de infecção no decorrer do tempo mostra-se útil como guia para o diagnóstico precoce e diferencial dos processos infecciosos nos transplantados cardíacos, na detecção de exposição ambiental excessiva que causariam desvios dessa distribuição e no desenvolvimento de estratégias preventivas efetivas (8).

Quanto ao tipo de infecção predominante no pós-operatório dos transplantados, a maioria dos grupos relata um predomínio de infecções bacterianas, seguidas por virais, fúngicas e protozoárias $(3,9)$. Em nosso estudo também notamos uma distribuição semelhante quanto à etiologia.

As infecções bacterianas em nossa casuística foram responsáveis pela maior causa de óbito: sepse em 6 pacientes, pneumonia em 6 e infecção intra abdominal em 2. Observamos um predomínio de infecções pulmonares o que também fol observado por UIP (3). Dentre os fatores predisponentes para tal condição citam-se a intubação orotraqueal prolongada, a circulação extracorpórea ou sangramentos prolongados e a depressão da função pulmonar causada por falência congestiva crônica. É importante ressaltar as dificuldades encontradas para diagnosticar processo infeccioso pulmonar no pós-operatório de cirurgia cardíaca e de transplante cardíaco ${ }^{(3)}$. A resposta inflamatória nos pacientes transplantados e imunodeprimidos está diminuída o que modifica ou retarda o aparecimento de lesões pulmonares na radiografia, além do que são várias as condições clínicas que podem causar febre e infiltrado pulmonar no pós-operatório, como rejeição e edema agudo de pulmão $(3,8)$. 
Para obter-se cura adequada das infecções pulmonares é muito importante um diagnóstico etiológico precoce e terapias específicas. Dessa forma, técnicas diagnósticas invasivas seriam justificadas nesses pacientes. $\mathrm{Na}$ maioria das vezes, em nosso maio, a obtenção de culturas da árvore traqueobrônquica usa métodos inadequados, como a cultura de secreção traqueal, sendo que a urgência do tratamento leva ao uso empírico de antimicrobianos.

As infecções bacterianas do trato urinário ocorreram de maneira significativa no estudo de UIP, principalmente por bactérias entéricas gram negativas, resultados semelhantes aos nossos achados. Tal fato pode ser devido à necessidade de manter a cateterização uretral no pós-operatório imediato.

Com relação as infecções superficial e profunda do sítio cirúrgico nos nossos pacientes, a evolução pode ser considerada favorável, sem óbitos observados, apesar da necessidade de reintervenção cirúrgica em 3 pacientes. MILLER et al.(9) em estudo multicêntrico relataram $3 \%$ de complicações de ferida operatória o que causou óbito em $22 \%$ dos pacientes.

O segundo tipo de infecção predominante em nossa casuística foi a viral, com $34(28,8 \%)$ episódios. Houve predominância da família Herpes viridae: vírus herpes simplex varicela zoster, Citomagalovírus. Todos os casos, com exceção de 1 que evoluiu para óbito causado por citomegalovirose disseminada, apresentaram boa evolução após o tratamento instituído. UIP (3) observou incidência semelhante de manifestação de vírus da família Herpes Viridae em seus pacientes, porém notou incidência maior de infecção pelo Citomegalovírus.

A maioria dos trabalhos internacionais chama a atenção para a infecção pelo Citomegalovírus e seus efeitos receptores, sendo muitas vezes a principal causa de infecção em alguns grupos (9). A baixa incidência de infecção por esse agente em nosso estudo provavelmente seja devido ao não diagnóstico adequado dessa condição, sendo que muitas infecções podem não terem sido notadas.

No que diz respeito à infecção causada por protozoários e em particular, a reativação da infecção pelo Trypanosoma cruzi nos transplantados por doença de Chagas, observamos 8 casos de reativação em 24 portadores dessa doença. $O$ reaparecimento da doença se manifestou principalmente pela presença de nódulos subcutâneos em membros inferiores.

As reativações da infecção pelo Trypanosoma cruzi podem estar diretamente relacio- nados à intensidade da imunodepressão utilizada e/ou à disfunção imunológica conferida pela doença de Chagas (7). Devido a isso, nos nossos pacientes foram utilizadas doses menores de ciclosporina nos primeiros 3 meses e também procedeu-se à retirada mais precoce do esquema imunossupressor.

No nosso meio, BOCCHI et al. (10) ao avaliarem os resultados de 22 pacientes chagásicos operados, notaram uma melhora dos resultados no decorrer do tempo com a redução da dose empregada de ciclosporina. Nesses pacientes foi utilizado o benzonidazol para tratamento dos episódios de reativação. CARVALHO et al. (11) também obtiveram bons resultados com o transplante cardíaco em 10 pacientes chagásicos e controle da parisitemia pelo T. cruzi com benzonidazol.

Nos nossos pacientes, para tratar os episódios de reativação, deu-se preferência ao análogo da purina, o alopurinol, devido aos potenciais efeitos colaterais do benzonidazol. $O$ alopurinol apresenta ótima tolerabilidade e baixa incidência de efeitos colaterais. A sua associação $\mathrm{com}$ as drogas imunossupressoras parece ser segura, com a monitorização rotineira dos pacientes (7).

Outro tipo de infecção causada por protozoário observada em nossos pacientes foi a toxoplasmose. O Toxoplasma gondii é parasita com potencial para causar doença grave em hospedeiros imunocomprometidos. Na grande maioria dos casos ocorre devido a transmissão através do órgão doador com exacerbação causada pelo regime de drogas imunodepressoras. O espectro clínico da doença em transplantados cardíacos varia desde quadros oligossintomáticos até formas disseminadas dependendo do nível de imunodepressão (3). Nos nossos casos o diagnóstico foi estabelecido em 4 ocasiões, sendo que 1 através de necropsia, 2 pela manifestação de coriorretinite e 1 através da biópsia miocárdica.

No que diz respeito a infecções fúngicas, a sua incidência em pacientes submetidos a transplante cardíaco tem sido oscilado entre $10 \%$ e $25 \%$. UIP(3) observou em 100 pacientes maior freqüência de infecção da cavidade oral, por Candida albicans, sem gravidade clínica, mas a causa de óbito foi fúngica em 3 ocasiões. MILLER et al. (9) observaram $7 \%$ de infecções fúngicas do seu total, mas, com uma mortalidade de $36 \%$.

Dentre as infecções fúngicas em nossos pacientes, observamos um predomínio de Candida albicans em cavidade oral, sem repercussões clínicas importantes. Também observamos uma esofagite estenosante causada por Candida albicans e 2 in- 
fecções pulmonares causadas por Pneumocystis carinii. Todos apresentaram boa evolução após o tratamento específico.

A infecção ainda é a principal causa de óbito, na maioria dos grupos, em pacientes submetidos a transplante cardíaco e causa morbidade significativa. Sendo assim, várias medidas têm sido preconizadas com a intenção de se evitar tais complicações. Dentre estas citam-se: a avaliação minuciosa do doador e do receptor, uso de antimicrobianos profiláticos, adequação da imunossupressão, etc. $O$ conhecimento dos tipos mais comuns de infecção em nosso meio e sua distribuição ao longo do tempo é de fundamental importância antes mesmo que o diagnóstico seja estabelecido. Mas, além disso, é necessário meIhorar os testes diagnósticos, os meios de monitorar a função imune e, também desenvolver novas terapias antimicobrianas para combater o desenvolvimento de resistência aos agentes infecciosos.

Os nossos dados mostram-se úteis para a orientação em nossa comunidade dos programas de transplantes, uma vez que traz a tona particularidades do nosso meio.

\section{CONCLUSÕES}

A infecção foi a principal causa de óbito nos nossos pacientes transplantados cardíacos. As infecções bacterianas predominaram e causaram a maior mortalidade principalmente através da manifestação de sepse e pneumonia.

Dentre as infecções bacterianas houve um predomínio de infecção pulmonar seguida de infecção do trato urinário.

As infecções causadas por vírus apareceram em segundo lugar em freqüência com predomínio do vírus da família Herpes viridae, mas sem causar situações clínicas de gravidade.

Dentre as infecções fúngicas, as causadas por Candida albicans foram as mais comuns, mas também sem gravidade clínica.

As infecções causadas pelo Toxoplasma gondii ocorreram principalmente através da manifestação clínica de coriorretinite.

Nos transplantados por doença de Chagas, a reativação da infecção pelo Trypanosoma cruzi pode ser controlada adequadamente com o uso de alopurinol.

Couto W J, Branco J N R, Almeida D, Carvalho A C, Vick R, Teles C A, Aguiar L F, Buffolo E Cardiac transplantation and infection. Rev Bras Cir Cardiovasc 2001; 16(2): 141-51.

ABSTRACT: Objective: To evaluate the incidence of infection, the etiological agents, to present the clinical aspects and the surgical morbi-mortality in patients who underwent cardiac transplant at Federal University of São Paulo.

Material and Methods: From November 1966 to June 1998, a total of 97 patients were operated by the UNIFESP Cardiovascular Surgery team and survived longer than 1 week after the transplantation and were studied retrospectively as far as infections. The age of the patients ranged from 3 to 63 years (average 44.4 13 years). Most of the patients had dilated myocardiopathy (46), or Chagas (24) or ischemis (23). The follow up ranged from 0.33 to 119 months (36 30.7 months)

Results: Of the 97 patients, $16(16.4 \%)$ had infection as the main cause of death, followed by rejection in $10(10.3 \%)$. The causes of infection were: bacterial sepsis in 6 patients, pneumonia in 6 , intra-abdomina infection in 2, toxoplasmosis in 1 and cytomegalovirus infection in 1. There were 142 infection episodes, bacterial $76(52.5 \%)$, viral 34 (28.8\%), fungi 20 (17.5\%) and protozoa 12 (12.4\%). There were 8 episodes of the reactivation were treated successfully with alopurinol.

Conclusions: Our data showed the predominance of bacterial infections as the cause of most mortality. In transplanted patients suffering from Chagas'disease, the reactivation of the disease may be adequately controlled by means of alopurinol. Such data serve as orientation in our community for our programs of transplants, since they show particular aspects of our enviroment.

DESCRIPTORS: Heart transplantation, infection. Heart transplantation, mortality. Heart transplantation, adverse effects. Infection, epidemiology. Infection, etiology. Infection, mortality. 


\section{REFERÊNCIAS BIBLIOGRÁFICAS}

1 Barnard C N - A human cardiac transplant: an interim report of a successful operation performed at grout Schuur Hospital, Cape Town. S Afr Med J 1967; 41: $1271-4$.

2 Décourt L V \& Zerbini E J - Transplante de coração humano: considerações sobre três casos. Rev Hosp Clin Fac Med São Paulo 1970; 25: 207-26.

3 Uip D E - Infecções em 100 pacientes submetidos à transplante cardíaco [Tese Doutorado] São Paulo: Faculdade de Medicina da Universidade de São Paulo, 1993. 95 p.

4 Branco J N R - Transplante cardíaco: a experiência da Universidade Federal de São Paulo [Tese LivreDocência] São Paulo: Universidade Federal de São Paulo - Escola Paulista de Medicina, 1997. 222p.

5 Lower R R \& Shumway N E - Studies in orthotopic homotransplantation of the canine heart. Surg Forum 1960; 11: 18-9.
6 Garner J S, Jarvis W R, Emori T G, Horan T C, Hughes $J \mathrm{M}-\mathrm{CDC}$ definitions for nosocomial infections, 1988. Am J Infect Control 1988; 16: 128-40.

7 Almeida D R - Transplante cardíaco no tratamento da miocardiopatia chagásica [Tese Doutorado] São Paulo: Universidade Federal de São Paulo - Escola Paulista de Medicina, 1996. 157p.

8 Fishmann J A \& Rubin $\mathrm{R} \mathrm{H}$ - Infection in organ: transplant recipients. $N$ Engl J Med 1988; 338: 1741-51.

9 Miller L W, Naftel D C, Bourge R C et al. - Infection after heart transplantation: a multiinstitutional study: Cardiac Transplant Research Database Group. J Heart Lung Transplant 1994; 13: 381-93.

10 Bocchi E A, Bellotti G, Mocelin A O et al. - Heart transplantation for chronic Chagas' heart disease. Ann Thorac Surg 1996; 61: 1727-33.

11 Carvalho V B, Sousa E F, Vila J H et al. - Heart transplantation in Chagas' disease: 10 years after the initial experience. Circulation 1996; 94: 1815-7. 